\title{
Assessment of a New Approach for Systematic Subsurface Drip Irrigation Management
}

\author{
Hédi Ben Ali, ${ }^{1}$ Moncef Hammami, ${ }^{2}$ Ahmed Saidi, ${ }^{3}$ and Rachid Boukchina ${ }^{4}$ \\ ${ }^{1}$ Agence de Promotion des Investissements Agricoles, 6000 Gabès, Tunisia \\ ${ }^{2}$ Laboratory of Hydraulic, High School of Engineers of Rural Equipment, Medjez el Bab, Tunisia \\ ${ }^{3}$ National Research Institute of Rural Engineering, Water and Forests (INRGREF), Rue Hédi EL Karray El Menzah IV, \\ BP 10, 2080 Ariana, Tunisia \\ ${ }^{4}$ Institut des Régions Arides, 6000 Gabès, Tunisia \\ Correspondence should be addressed to Ahmed Saidi; saidiahmed44@gmail.com
}

Received 5 December 2016; Accepted 26 January 2017; Published 20 February 2017

Academic Editor: Manuel Tejada

Copyright (C) 2017 Hédi Ben Ali et al. This is an open access article distributed under the Creative Commons Attribution License, which permits unrestricted use, distribution, and reproduction in any medium, provided the original work is properly cited.

\begin{abstract}
This paper aimed to assess the reliability of a new approach that provides systematic irrigation management based on fixed water suction in the vadose zone. Trials were carried out in the experimental farm of IRA Gabès on subsurface drip irrigated (SDI) tomato plot. The SDI system was designed so that the soil water content is to be maintained within prescribed interval ascertaining the best plant growth. Irrigation management was systematically monitored by water suction evolution in the vadose zone. Recorded results showed that all-over irrigation season lateral pressure head ranged within $93.3 \pm 20.0 ; 119.95 \pm 53.35$ and $106.6 \pm 40.0 \mathrm{mb}$, respectively, at the upstream, middle, and downstream. The correspondent lateral pressure head distribution uniformity ranged within $97.1 \%$ and $99.6 \%$. Soil water content varied within $0.2175 \pm 0.0165 ; 0.206 \pm 0.0195$ and $0.284 \pm 0.100$ beneath the inlet, the behalf, and the lateral end tip. The correspondent soil water distribution uniformity was higher than $80.7 \%$ all-over irrigation season. Based on the recorded results, the proposed approach could be a helpful tool for accurate SDI systems design and best water supplies management. Nevertheless, further trials are needed to assess the approach reliability in different cropping conditions.
\end{abstract}

\section{Introduction}

Water scarcity is among the main problems to be faced by many societies and the world in the 21st century [1]. The use of water-efficient irrigation is one of the most practical options to reduce global water scarcity [2]. Subsurface drip irrigation (SDI) provides the opportunity to record consistently water use efficiency over traditional methods, including surface drip irrigation (DI) [3-5]. Several field trials revealed relevant profits on managing SDI for crops' production. In fact, SDI system allows the direct application of water to the rhizosphere maintaining dry the nonrooted top soil. This pattern generates numerous advantages such as minimizing soil evaporation and then evapoconcentration phenomenon [6]. Comparing evaporation from surface and subsurface drip irrigation systems, Evett et al. [7] reported that 51 and $81 \mathrm{~mm}$ were saved with drip laterals buried at $15 \mathrm{~cm}$ and $30 \mathrm{~cm}$, respectively. Patel and Rajput [8] recorded maximum onion yield $\left(25.7 \mathrm{tha}^{-1}\right)$ with drip laterals buried at $10 \mathrm{~cm}$, whereas Ombódi et al. [9] recorded an average yield ranging between 40.7 and $54.6 \mathrm{tha}^{-1}$ for onion in irrigated conditions.

Also, with SDI systems more uniform moisture distribution, in the vadose zone (than with drip irrigation systems), was observed, and thus drainage and surface evaporation were less with SDI $[10,11]$. Automation of irrigation systems has the potential to provide maximum water use efficiency by maintaining soil moisture within an optimal interval ascertaining the best plant growth [6].

This experimental study aimed to assess the reliability of a new approach for SDI laterals' design accounting for the soil water-retention characteristics and the roots water extraction. The proposed approach provides systematic irrigation management based on fixed water suctions in the vadose zone. 


\section{Material and Methods}

2.1. Site. Experiments were carried out in the experimental station of Arid Regions Institute of Chenchou (Gabès) whose geographical coordinates are latitude $=33.88^{\circ}$ North, longitude $=9.79^{\circ}$ East, and at an altitude of $59 \mathrm{~m}$. Average monthly temperature ranges were between $10.4^{\circ} \mathrm{C}$ (January) and $28.6^{\circ} \mathrm{C}$ (August). Average annual rainfall is $162 \mathrm{~mm}$ while potential evapotranspiration (ETP) is $1430 \mathrm{~mm} /$ year.

Field trials were performed from May 26th up to September the 15th 2014 in tomato (Feranzi variety) plot $(86.0 \times$ $8.0 \mathrm{~m}^{2}$ ). Seedlings' rows were $1.60 \mathrm{~m}$ distant while crop plants were $0.40 \mathrm{~m}$ apart. Each row crop was irrigated by a single SDI lateral buried at $15 \mathrm{~cm}$ depth. According to Najafi [12] and Zotarelli et al. [13], tomato crop irrigated with laterals buried at $Z_{d}=15 \mathrm{~cm}$ depth's leads to the better yields, whereas Machado and Oliveira [14] found that tomato roots were concentrated mainly within the $[0-40 \mathrm{~cm}]$ top soil layer under DI and SDI irrigation systems.

For soil physical characterization, four representative profiles were randomly chosen (within the plot). In each profile, soil samples were collected on four layers: $0-20$, $20-40,40-60$, and $60-80 \mathrm{~cm}$. Analyses were focused on properties that account for soil moisture holding and water suction evolution, namely: texture, bulk density $\left(D_{a}\right)$, and water content-pressure head relationship.

2.2. Method. According to Hammami et al. [6], the minimum pressure required at the upstream end of nontapered flat SDI lateral is

$$
h_{L m}=Z_{d}+J_{L}+\Delta h_{\mathrm{min}}+h_{\mathrm{op}}-\Delta h_{\mathrm{op}}
$$

whereas the maximum pressure head $\left(h_{L M}\right)$ required at the upstream end of the lateral is

$$
h_{L M}=Z_{d}+J_{L}+\Delta h_{\text {min }}+h_{\mathrm{op}}+\Delta h_{\mathrm{op}}
$$

with $h_{L m}$ and $h_{L M}$ being minimum and maximum required pressure heads $(\mathrm{m})$ at the beginning of the lateral. $Z_{d}$ is laterals depth of burial (m). $J_{L}$ are total pressure head losses $(\mathrm{m})$ along the lateral. $h_{\mathrm{op}}$ is optimal soil water suction $(\mathrm{m})$ for crop's growth. $\Delta h_{\mathrm{op}}$ is interval of variation of the optimal soil suction $(\mathrm{m}) . \Delta h_{\mathrm{min}}$ is minimum differential pressure head for emitters operating.

According to Hammami et al. [6], the soil capillary capacity $(C)$ is the highest if the second derivative of the soil moisture content with respect to the suction head is zero. Thus, using van Genuchten [15] model,

$$
\theta(h)=\theta_{r}+\frac{\left(\theta_{s}-\theta_{r}\right)}{\left(1+(\alpha|h|)^{n}\right)^{m}} .
$$

The optimal suction is straight fully derived as follows:

$$
h_{\mathrm{op}}=-\frac{m^{1 / n}}{\alpha} \text {. }
$$

Nonlinear adjustment of discrete data $(\theta, h)$ allows deducing $\theta_{r}, \alpha$, and $n$ values from the fitted expression $\theta(h)(14)$.
Substituting $m, \alpha$, and $n$ in (4) gives the correspondent $h_{\mathrm{op}}=$ $-1.47 \mathrm{~cm}$.

Gärdenäs et al. [16] reported that tomato crop tolerates (without noticeable yield decrease) a soil water pressure variation in the interval $[-800,-2 \mathrm{~cm}]$. Then, $\Delta h_{\mathrm{op}}= \pm 400 \mathrm{~cm}$ was considered. Therefore, for an optimal tomato crop's growth, the soil water pressure $(h)$ should be maintained within the interval as follows:

$$
\begin{gathered}
h_{\text {op }}+400 \geq h(\mathrm{~cm}) \geq h_{\text {op }}-400 \Longleftrightarrow \\
398.53 \geq h(\mathrm{~cm}) \geq-401.47 \mathrm{~cm} .
\end{gathered}
$$

To avoid any soil saturation risk, we retained

$$
00.00>h(\mathrm{~cm}) \geq-401.47 .
$$

Consequently, the correspondent optimum water content $\left(\theta_{\text {op }}\right)$ should be maintained within the interval as follows:

$$
0.385>\theta_{\text {op }} \geq 0.184 \mathrm{~cm}^{3} \mathrm{~cm}^{-3} \text {. }
$$

A minimum value $\Delta h_{\min }$ for the emitter operation is required. This threshold $\Delta h_{\text {min }}$ is dependent on the structural form, dimension, and material of the emitter pathway. For any emitter model, $\Delta h_{\text {min }}$ may be inferred from the emitter discharge-pressure head relationship provided by the manufacturer. Then, the minimum pressure $h_{\text {min }}^{*}$ into emitter should respect the following condition:

$$
h_{\text {min }}^{*} \geq h_{\text {op }}+\Delta h_{\text {min }} .
$$

A trapezoidal labyrinth long-path emitter with a minimal differential operating pressure head of $\Delta h_{\text {min }}=500 \mathrm{~cm}$ was used; then

$$
h_{\min }^{*} \geq 498.53 \mathrm{~cm} \text {. }
$$

So, the required pressure in the emitters should be between $h_{\text {req }}^{\text {min }}$ and $h_{\text {req }}^{\max }$, with

$$
\begin{aligned}
& h_{\text {req }}^{\text {min }}=h_{\text {op }}-\Delta h_{\text {op }}+\Delta h_{\text {min }} \Longrightarrow \\
& h_{\text {req }}^{\text {min }}=98.53 \mathrm{~cm} \\
& h_{\text {req }}^{\text {max }}=h_{\text {op }}+\Delta h_{\text {op }}+\Delta h_{\text {min }} \Longrightarrow \\
& h_{\text {req }}^{\text {max }}=500.0 \mathrm{~cm} .
\end{aligned}
$$

Since the pressure head, in the soil around the laterals, should vary between -401.47 and $00.00 \mathrm{~cm}$, emitters discharge $q(\mathrm{l} / \mathrm{h})$ should be maintained between

$$
2.15 \geq q(\mathrm{l} / \mathrm{h}) \geq 0.75 .
$$

Each lateral is equipped with $N=86 / 0.4=215$ emitters; therefore its flow rate $Q$ should comply with

$$
160.5 \leq Q(1 / h) \leq 462.5 .
$$

The proper laterals' diameter used to ensure the maximum discharge $\left(Q_{\max }=462.5 \mathrm{l} / \mathrm{h}\right)$ was $\varnothing=16 \mathrm{~mm}$. Thus 
using Watters and Keller [17] formula, the total lateral's pressure head loss is equal to

$$
J_{L}=78 \mathrm{~cm} .
$$

Finally, the maximum inlet lateral pressure head was determined using (2) as follows:

$$
h_{L M}=641.53 \mathrm{~cm} .
$$

In order to maintain the lateral inlet pressure head $\left(h_{L I}\right)$ constant (equal to or less than $641.53 \mathrm{~cm}$ ), two interconnected reservoirs were used. Water was pumped to the first reservoir $\left(\right.$ capacity $=120.0 \mathrm{~m}^{3}$ ) that supplies the second one (capacity $=1.00 \mathrm{~m}^{3}$ ) which diverts water to the irrigation network. The water level inside the second reservoir was maintained constant thanks to a mechanical float. The pump was controlled by an electric float (Figure 1).

To record lateral's pressure head $\left(h_{L}\right)$, suction, and the correspondents soil water content $\theta(h)$ spatial-temporal evolutions, three measurement sites were set along the lateral: at the inlet $X=0.0 \mathrm{~m}$, at the behalf $X=L / 2$, and at the end tip $X=L$. In each measurement site, the installed pieces of equipment were a $U$ piezometer (connected on the lateral), three TDR access tubes, and 9 Watermark probes (three probes per layer buried at the distances $R=0.0 \mathrm{~cm}$; $R=16.0 \mathrm{~cm}$; and $R=32.0 \mathrm{~cm}$ perpendicular to the lateral (Figure 2)). Soil water content values were recorded for the following depths: $Z=10 ; 15 ; 30 ; 50$; and $70 \mathrm{~cm}$. A water meter device has been installed at the laterals' inlet in order to record the delivered water volume. Simultaneously lateral flow rate was measured several times a day. Such measurements allow determining the average daily flow rate variation (from crop transplantation to harvest season). In sum, the following variables were recorded:

(i) The spatial-temporal soil water content $\theta(x, z, t)$ variation within the root zone around the lateral.

(ii) The spatial-temporal soil water suction $h(x, z, t)$ variation.

(iii) The spatial-temporal pressure head $h_{L}(x, t)$ variation inside the lateral.

(iv) The temporal lateral's flow rate $Q(t)$ variation.

\section{Results and Discussions}

3.1. Physical Soil Characteristics. Mean values of particle size proportion, bulk density $\left(D_{a}\right)$, and soil water contents (at saturation $\theta_{s}$, field capacity $\theta_{c}$, and wilting point $\theta_{w}$ ) for the four sampled soil layers are summarized in Table 1. These results showed that clay and silt proportions are relatively equiponderant all-over the soil profile while sand proportion decreases from the surface up to $60 \mathrm{~cm}$ depth. So the experimental plot is loamy sand textured soil all-over the profile but becomes as fine as it is deep. The bulk density and the soil holding capacity (roughly $100 \mathrm{~mm} / \mathrm{m}$ ) values confirm such texture tendency.

The $\theta_{i}$ and their $h_{i}$ correspondent values (measured in situ) were fitted to van Genuchten [15] formula, using RETC model (Figure 3). So the inferred analytical expression of the soil retention curve was

$$
\theta=0.096+\frac{0.289}{\left(1+(0.01321|h|)^{4.319}\right)^{0.768}} .
$$

3.2. Soil Moisture Distribution. Temporal soil water content $\theta$ evolution in the soil depth $Z=10 \mathrm{~cm}$, at the inlet $(X=0)$, at the behalf $(X=L / 2)$, and at the lateral end tip $(X=L)$, is depicted in Figure 4. All-over irrigation season, recorded $\theta$ values ranged within $0.385>\theta \geq 0.184 \mathrm{~cm}^{3} \mathrm{~cm}^{-3}$ for $X=0$ and $X=L / 2$. Then, it was maintained within the predicted interval $0.385>\theta_{\mathrm{op}} \geq 0.184 \mathrm{~cm}^{3} \mathrm{~cm}^{-3}$ (6) optimal for the tomato growth, while, underneath lateral end tip $(X=L), \theta$ values were almost slightly lower than $0.184 \mathrm{~cm}^{3} \mathrm{~cm}^{-3}$. This difference could be attributed to the total pressure head losses occurring along the lateral that subsequently induces a slight emitter discharge decrease. Safi et al. [18] reported that an increase of SDI laterals' length leads to a decrease of all uniformity parameters. Also, such discrepancy could be due to measurement errors on $\theta$ and/or $h$ values. Haverkamp et al. [19] reported that an error of only $2 \%$ of $\theta$ value could cause a relative error of $24 \%$ of soil water pressure head. The same trends of the soil moisture distribution were recorded in the soil depth $Z=15 \mathrm{~cm}$ (Figure 5), where $\theta$ remained higher than the minimum prescribed threshold $\theta\left(h_{\mathrm{op}}-\Delta h_{\mathrm{op}}\right)=0,184 \mathrm{~cm}^{3} \mathrm{~cm}^{-3}$, at $X=0$ and $X=L / 2$ but still slightly lower than that threshold at the lateral end tip. Such trend confirms the above finding. In the soil depth $Z=30 \mathrm{~cm}$, water content values remained roughly confused with the prescribed minimum threshold (at the inlet $X=0)$ at the lateral behalf $(X=L / 2)$ but slightly lower (at the end tip $X=L$ ) than such threshold $0.184 \mathrm{~cm}^{3} \mathrm{~cm}^{-3}$ (Figure 6). However, in the deeper soil layers $Z=50 \mathrm{~cm}$ and $Z=70 \mathrm{~cm}$, water content values remained approximately invariant lower than $0.184 \mathrm{~cm}^{3} \mathrm{~cm}^{-3}$ all-over irrigation season and for whole lateral length (Figures 7 and 8). These results could be explained by the fact that supplied water (by the lateral) was not so enough to reach such depths. So, deep water and then nutrients losses were negligible. Thus the used approach could be useful tool to improve SDI irrigation efficiency.

The above results validate the systematic SDI irrigation management. Lazarovitch et al. [20] proved that soil hydraulic properties affect outlets flow rate in SDI irrigation system. To assess the water distribution uniformity along the laterals, we determined the coefficient of uniformity $(\mathrm{CU})$ values throughout irrigation season.

$$
\mathrm{CU}=\left(1-\frac{\sum\left|\theta_{a}-\theta_{(x i z z i)}\right|}{N \cdot \theta_{a}}\right) 100,
$$

where $\theta_{a}$ is average soil water content for different depths in the three soil profiles $(X=0, X=L / 2$, and $X=L)$ and, at a given date, $\theta_{(x i, z i)}$ is soil water content in the coordinates ( $x i$, $z i$ ) and $N$ is number of the sampled points.

The recorded CU values are always higher than $80.7 \%$ and the mean value was $84,3 \%$. These results confirm those of Ben 


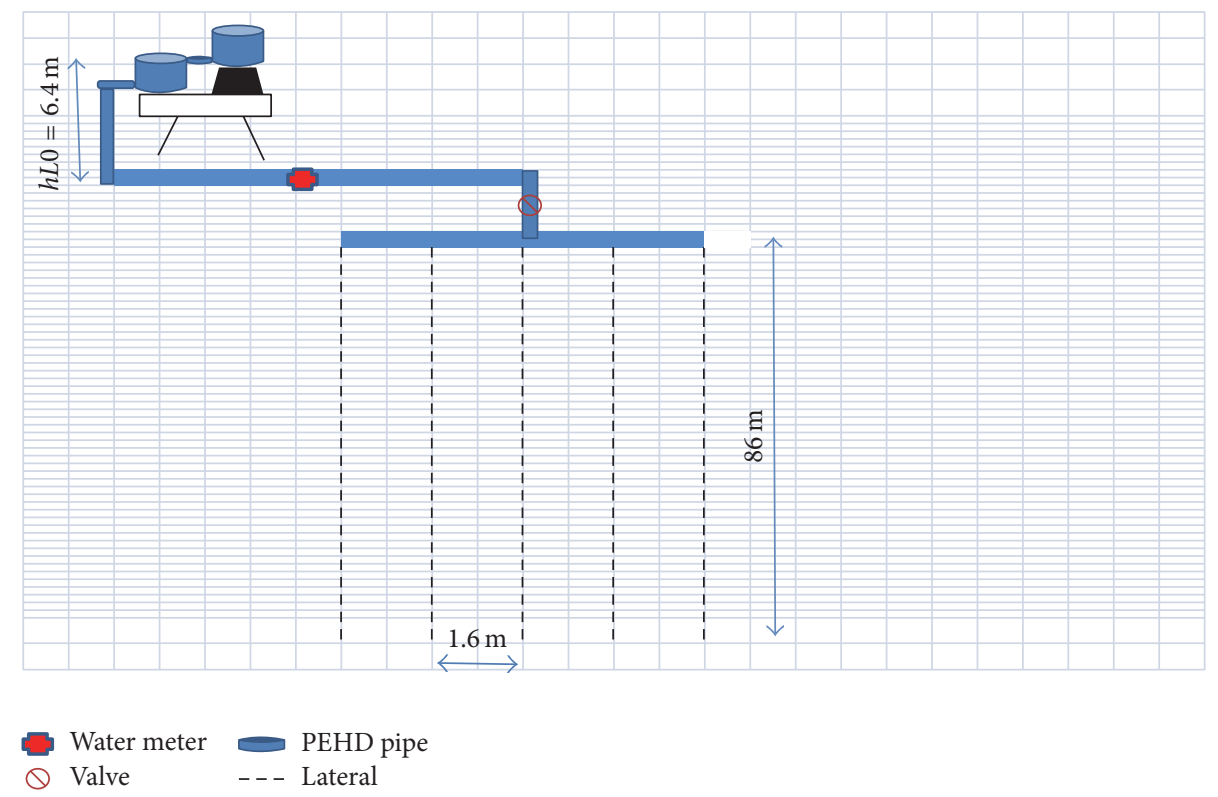

FIGURE 1: Experimental layout scheme.

TABLE 1: Soil physical characteristics.

\begin{tabular}{lccccccc}
\hline Soil layer $(\mathrm{cm})$ & Sand $(\%)$ & Silt $(\%)$ & Clay $(\%)$ & $D_{a}\left(\mathrm{~g} / \mathrm{cm}^{3}\right)$ & $\theta_{c}(\%)$ & $\theta_{w}(\%)$ & $\theta_{s}(\%)$ \\
\hline $0-20$ & 22 & 73 & 5 & 1.56 & 1.62 & 21.4 & 38.5 \\
$20-40$ & 19 & 77 & 4 & 1.62 & 18.7 & 36.1 \\
$40-60$ & 11 & 85 & 3 & 1.53 & 17.2 & 8.8 \\
$60-80$ & 17 & 80 & 3 & 7.4 & 42.4 \\
\hline
\end{tabular}

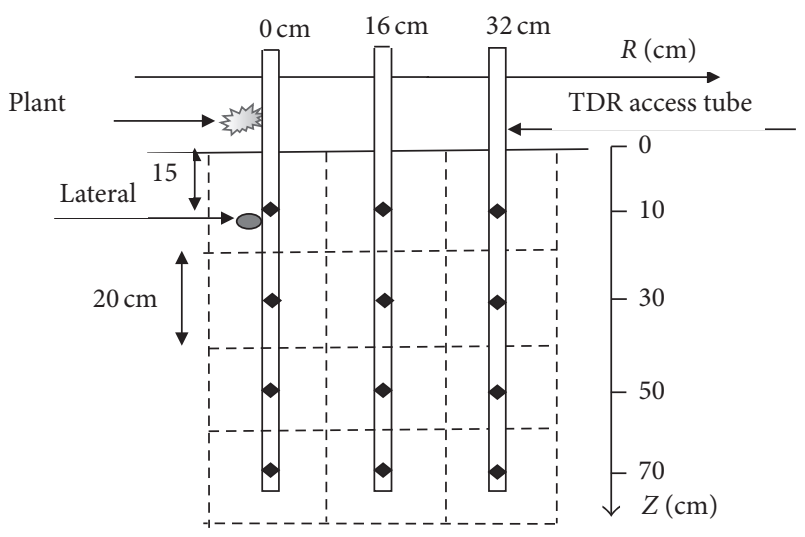

Figure 2: Profile of a measurement site.

Ali et al. [3] who reported that soil water content underneath SDI system was always higher and especially varied within narrower interval than under drip irrigation system. Gil et al. [21] recorded a lower variability of buried emitters' discharges compared to on surface ones.

3.3. Soil Suction Distribution. Temporal soil suction evolution in the depth $Z=15 \mathrm{~cm}$ for the three sites $X=0$;

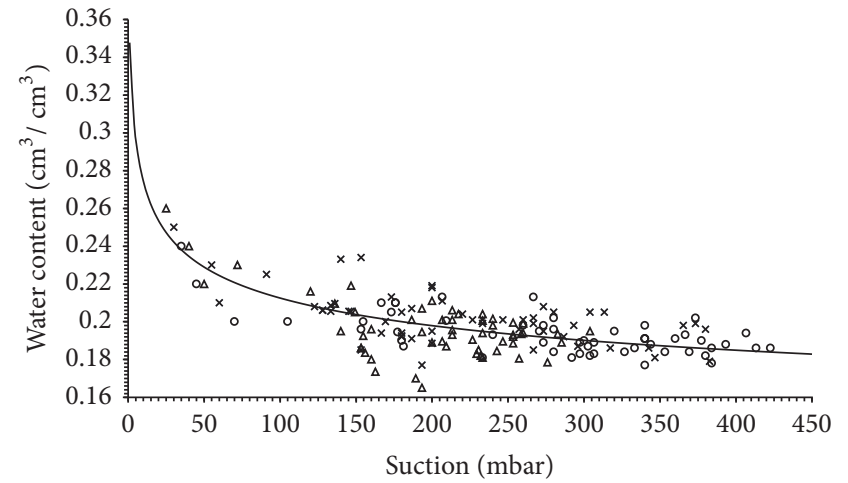

FIgURE 3: Soil retention curve $\theta(h)$ fitted (solid line) against experimental data determined at $Z=10 \mathrm{~cm}(\times), Z=30 \mathrm{~cm}(\triangle)$, and $Z=50 \mathrm{~cm} \mathrm{(o)} \mathrm{depths.}$

$X=L / 2$; and $X=L$ along the lateral is shown in Figure 9. Throughout irrigation season, the soil pressure $(h)$ varied within the following intervals: $[-73.3 \geq h(\mathrm{mb}) \geq-113.3]$, $[-66.6 \geq h(\mathrm{mb}) \geq-173.3]$, and $[-66.66 \geq h(\mathrm{mb}) \geq$ -146.7], respectively, at the abscissas $(X=0),(X=L / 2)$, and $X=L$. Thus it was ranged within the optimal predicted values $\left(5^{\prime}\right)$. Yet, neither saturation risks nor deep percolation 


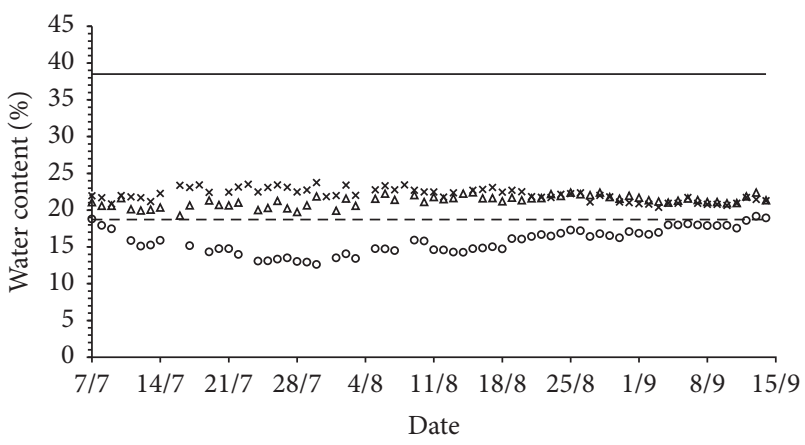

FIgURE 4: Temporal soil water content variation in the soil depth $Z=10 \mathrm{~cm}$ : at the inlet $X=0(\times)$, at the behalf $X=L / 2(\triangle)$, and at the lateral end tip $X=L(\mathrm{o})$ against $\left(\theta_{\mathrm{op}}+\Delta \theta_{\mathrm{op}}\right)$ solid and $\left(\theta_{\mathrm{op}}-\Delta \theta_{\mathrm{op}}\right)$ dashed lines.

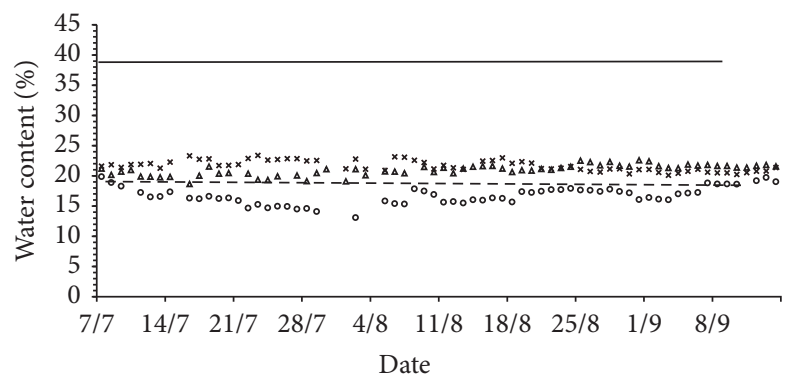

FIgURE 5: Temporal soil water content variation in the soil depth $Z=15 \mathrm{~cm}$ : at the inlet $X=0(\times)$, at the behalf $X=L / 2(\triangle)$, and at the lateral end tip $X=L(\mathrm{o})$ against $\left(\theta_{\mathrm{op}}+\Delta \theta_{\mathrm{op}}\right)$ solid and $\left(\theta_{\mathrm{op}}-\Delta \theta_{\mathrm{op}}\right)$ dashed lines.

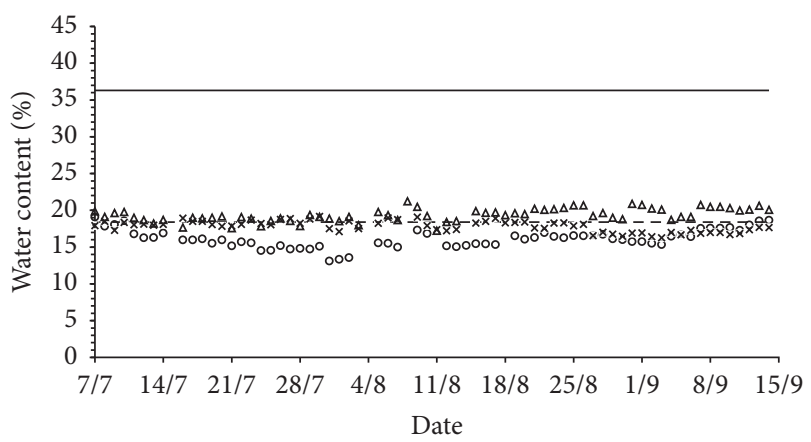

FIGURE 6: Temporal soil water content variation in the soil depth $Z=30 \mathrm{~cm}$ : at the inlet $X=0(\times)$, at the behalf $X=L / 2(\triangle)$, and at the lateral end tip $X=L(\mathrm{o})$ against $\left(\theta_{\mathrm{op}}+\Delta \theta_{\mathrm{op}}\right)$ solid and $\left(\theta_{\mathrm{op}}-\Delta \theta_{\mathrm{op}}\right)$ dashed lines.

water losses were recorded. Yao et al. [22] reported that the back pressure risk (or over pressure) occurring underneath subsurface lateral could be addressed by rigorous network design.

3.4. Lateral Pressure Head and Flow Rate. Because the pressure head $H$ in the supplying reservoir was maintained constant equal to $641.53 \mathrm{~cm}$, the pressure head at the lateral inlet $(X=0)$ remained also constant $(H \approx 640 \mathrm{~cm})$. However, $H$ values inside the behalf and at the lateral end

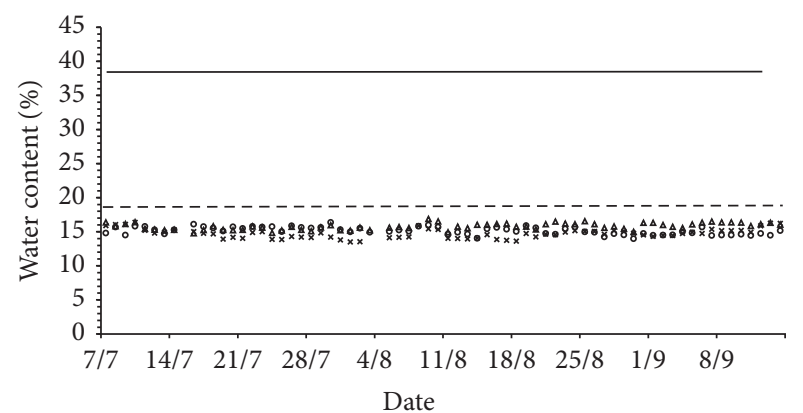

FIGURE 7: Temporal soil water content variation in the soil depth $Z=50 \mathrm{~cm}$ : at the inlet $X=0(\times)$, at the behalf $X=L / 2(\triangle)$, and at the lateral end tip $X=L($ o $)$ against $\left(\theta_{\text {op }}+\Delta \theta_{\text {op }}\right)$ solid and $\left(\theta_{\text {op }}-\Delta \theta_{\text {op }}\right)$ dashed lines.

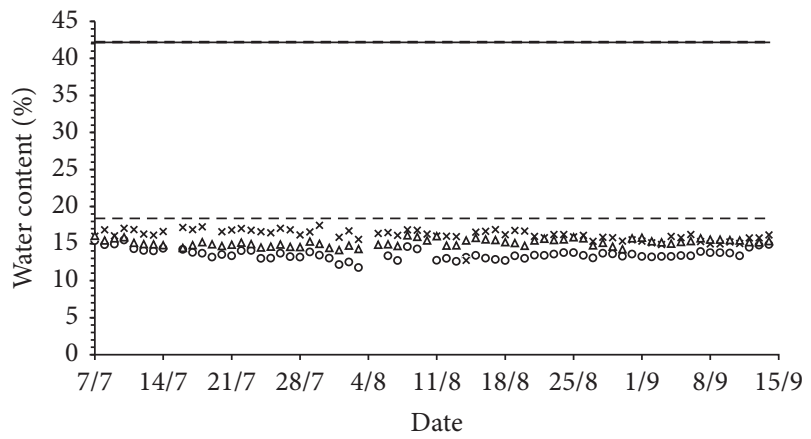

Figure 8: Temporal soil water content variation in the soil depth $Z=70 \mathrm{~cm}$ : at the inlet $X=0(\times)$, at the behalf $X=L / 2(\triangle)$, and at the lateral end tip $X=L(\mathrm{o})$ against $\left(\theta_{\mathrm{op}}+\Delta \theta_{\mathrm{op}}\right)$ solid and $\left(\theta_{\mathrm{op}}-\Delta \theta_{\mathrm{op}}\right)$ dashed lines.

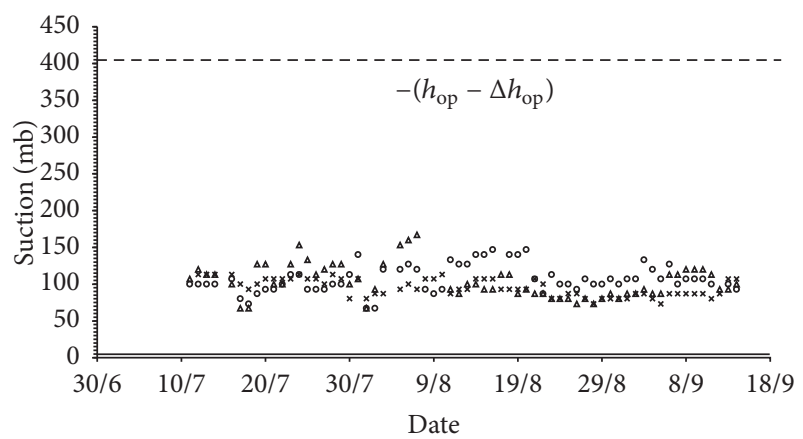

FIgURE 9: Temporal soil suction variation around the inlet $X=0$ $(\times)$, the behalf $X=L / 2(\triangle)$, and the lateral end tip $X=L(\mathrm{o})$ compared to the minimum (dashed line) and the maximum (solid line) required values.

tip were slightly lowered (ranged between 600 and $640 \mathrm{~cm}$ ) (Figure 10). Such slight variation could be attributed to the linear and nonlinear head losses along the lateral. Though the lateral inlet pressure head was maintained constant, the correspondent flow rate $Q_{L}$ was noticeably variable within $236 \geq Q_{L}(l / h) \geq 184$ but ranged within the fixed interval (11). Such variation could be explained by the soil (around the lateral) suction variation due to the soil water redistribution enhanced essentially by roots' water uptake. It should be 


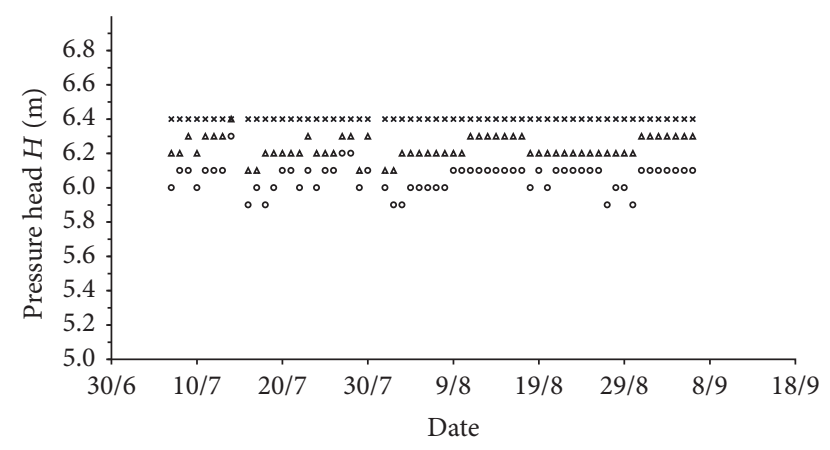

FIGURE 10: Pressure head values recorded at the inlet $X=0(\times)$, the behalf $X=L / 2(\triangle)$, and at the lateral end tip $X=L(\mathrm{o})$.

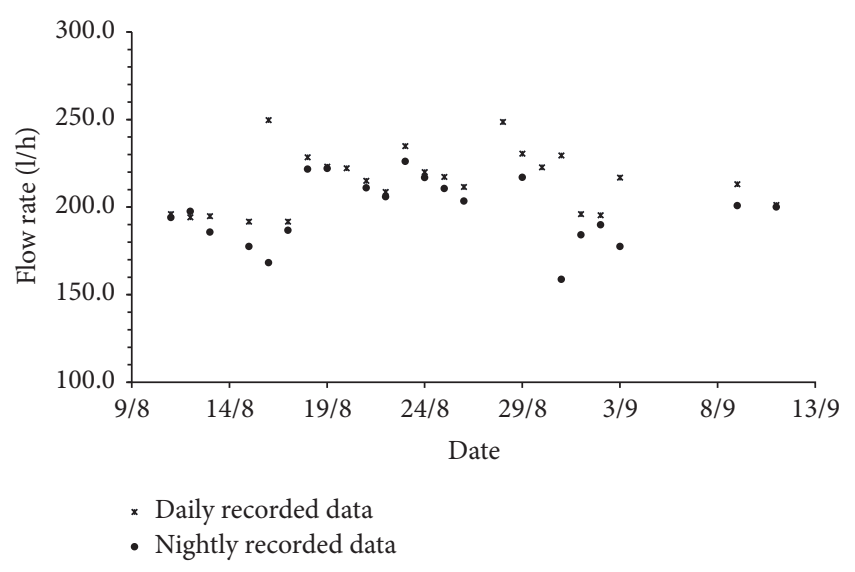

FIGURE 11: Lateral inlet discharge variation.

stressed that daily lateral discharge was always higher than nightly one (Figure 11). This slight difference (between daily and nightly discharges) highlighted the higher roots' water uptake enhanced by intensive physiologic activities by day times.

\section{Conclusion}

The objective of this work aimed to check the reliability of a new approach of SDI laterals design for a systematic irrigation management monitored by soil suction variation close to the outlets. Recorded results showed that, without human intervention for irrigation management, water content, in the soil layer $0-40 \mathrm{~cm}$, remained within the interval ]$\left.\theta\left(h_{\text {opt }}+\Delta h_{\text {opt }}\right) ; \theta\left(h_{\text {opt }}-\Delta h_{\text {opt }}\right)\right]$, corresponding to the optimal humidity interval for tomato growth. Soil water content in the deep layers $(Z=50 \mathrm{~cm}$ and $Z=70 \mathrm{~cm})$ remained roughly constant but lower than $\theta\left(h_{\mathrm{opt}}-\Delta h_{\mathrm{opt}}\right)$. So neither saturation risks nor water and nutrients losses by deep percolation were observed within the vadose zone. In addition, irrigation water uniformity along the lateral was almost higher than $80.7 \%$. So the design procedure illustrated in this paper provides the appropriate emitters discharge and the inlet lateral pressure head that fit the plant roots water uptake. Even though, soil water content recorded at the lateral end tip remained lower than the minimum optimal threshold throughout the entire cropping cycle. Therefore, the proposed approach could be an efficient tool for rigorous SDI lateral design. But further field trials are needed to effectively confirm such finding.

\section{Competing Interests}

The authors declare that they have no competing interests.

\section{References}

[1] FAO, Coping with Water Scarcity. Challenge of the Twenty-First Century, UN Water, 2007, http://www.fao.org/nr/water/docs/ escarcity.pdf.

[2] L. Levidow, D. Zaccaria, R. Maia, E. Vivas, M. Todorovic, and A. Scardigno, "Improving water-efficient irrigation: prospects and difficulties of innovative practices," Agricultural Water Management, vol. 146, pp. 84-94, 2014.

[3] H. Ben Ali, M. Hammami, R. Boukhchina, and A. Saidi, "Comparative study between surface and subsurface drip irrigation systems: case of potato crop," International Journal of Innovation and Applied Studies, vol. 6, no. 4, pp. 860-870, 2014.

[4] B. Douh and A. Boujelben, "Diagnosis of subsurface drip irrigation practices in Tunisia: impacts on soil water storage variation, corn yield and water use efficiency," Larhyss Journal, no. 10, pp. 115-126, 2012 (French).

[5] N. Patel and T. B. S. Rajput, "Effect of drip tape placement depth and irrigation level on yield of potato," Agricultural Water Management, vol. 88, no. 1-3, pp. 209-223, 2007.

[6] M. Hammami, K. Zayani, and H. Ben Ali, "Required lateral inlet pressure head for automated subsurface drip irrigation management," International Journal of Agronomy, vol. 2013, Article ID 162354, 6 pages, 2013.

[7] S. R. Evett, T. A. Howell, and A. D. Schneider, "Energy and water balances for surface and subsurface drip irrigated corn," in Proceedings of the 5th International Micro Irrigation Congress, pp. 135-140, Orlando, Fla, USA, 1995.

[8] N. Patel and T. B. S. Rajput, "Dynamics and modeling of soil water under subsurface drip irrigated onion," Agricultural Water Management, vol. 95, no. 12, pp. 1335-1349, 2008.

[9] A. Ombódi, N. Koczka, A. Lugasi, H. G. Daood, M. Berki, and L. Helyes, "Nutritive constituents of onion grown from sets as affected by water supply," HortScience, vol. 48, no. 12, pp. 15431547, 2013.

[10] G. S. Ghali and Z. J. Svehlik, "Soil-water dynamics and optimum operating regime in trickle-irrigated fields," Agricultural Water Management, vol. 13, no. 2-4, pp. 127-143, 1988.

[11] C. J. Phene, K. R. Davis, R. B. Hutmacher, and R. L. McCormick, "Advantages of subsurface irrigation for processing tomato," Acta Horticulturae, vol. 200, pp. 101-114, 1987.

[12] P. Najafi, "Effects of using subsurface drip irrigation and treated municipal waste water in irrigation of tomato," Pakistan Journal of Biological Sciences, vol. 9, no. 14, pp. 2672-2676, 2006.

[13] L. Zotarelli, J. M. Scholberg, M. D. Dukes, R. Muñoz-Carpena, and J. Icerman, "Tomato yield, biomass accumulation, root distribution and irrigation water use efficiency on a sandy soil, as affected by nitrogen rate and irrigation scheduling," Agricultural Water Management, vol. 96, no. 1, pp. 23-34, 2009.

[14] R. M. A. Machado and G. M. R. Oliveira, "Tomato root distribution, yield and fruit quality under different subsurface drip irrigation regimes and depths," Irrigation Science, vol. 24, no. 1, pp. 15-24, 2005. 
[15] M. T. van Genuchten, "Closed-form equation for predicting the hydraulic conductivity of unsaturated soils," Soil Science Society of America Journal, vol. 44, no. 5, pp. 892-898, 1980.

[16] A. I. Gärdenäs, J. W. Hopmans, B. R. Hanson, and J. Šimůnek, "Two-dimensional modeling of nitrate leaching for various fertigation scenarios under micro-irrigation," Agricultural Water Management, vol. 74, no. 3, pp. 219-242, 2005.

[17] G. Z. Watters and J. Keller, "Trickle irrigation tubing hydraulics," Tech. Ref. 78-2015, ASCE, Reston, Va, USA, 1978.

[18] B. Safi, M. R. Neyshabouri, A. H. Nazemi, S. Massiha, and S. M. Mirlatifi, "Water application uniformity of a subsurface drip irrigation system at various operating pressures and tape lengths," Turkish Journal of Agriculture and Forestry, vol. 31, no. 5, pp. 275-285, 2007.

[19] R. Haverkamp, M. Vauclin, J. Touma, P. J. Wierenga, and G. Vachaud, "Comparison of numerical simulation models for one-dimensional infiltration," Soil Science Society of America Journal, vol. 41, no. 2, pp. 285-294, 1977.

[20] N. Lazarovitch, U. Shani, T. L. Thompson, and A. W. Warrick, "Soil hydraulic properties affecting discharge uniformity of gravity-fed subsurface drip irrigation systems," Journal of Irrigation and Drainage Engineering, vol. 132, no. 6, pp. 531-536, 2006.

[21] M. Gil, L. Rodríguez-Sinobas, L. Juana, R. Sánchez, and A. Losada, "Emitter discharge variability of subsurface drip irrigation in uniform soils: effect on water-application uniformity," Irrigation Science, vol. 26, no. 6, pp. 451-458, 2008.

[22] W. W. Yao, X. Y. Ma, J. Li, and M. Parkes, "Simulation of point source wetting pattern of subsurface drip irrigation," Irrigation Science, vol. 29, no. 4, pp. 331-339, 2011. 


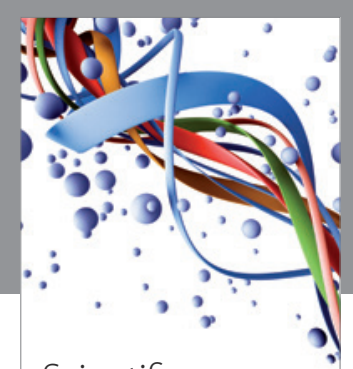

Scientifica
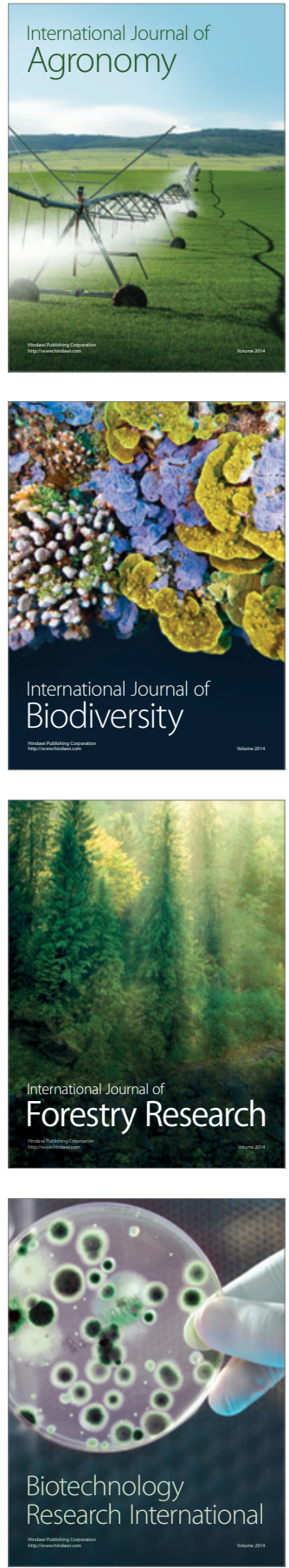
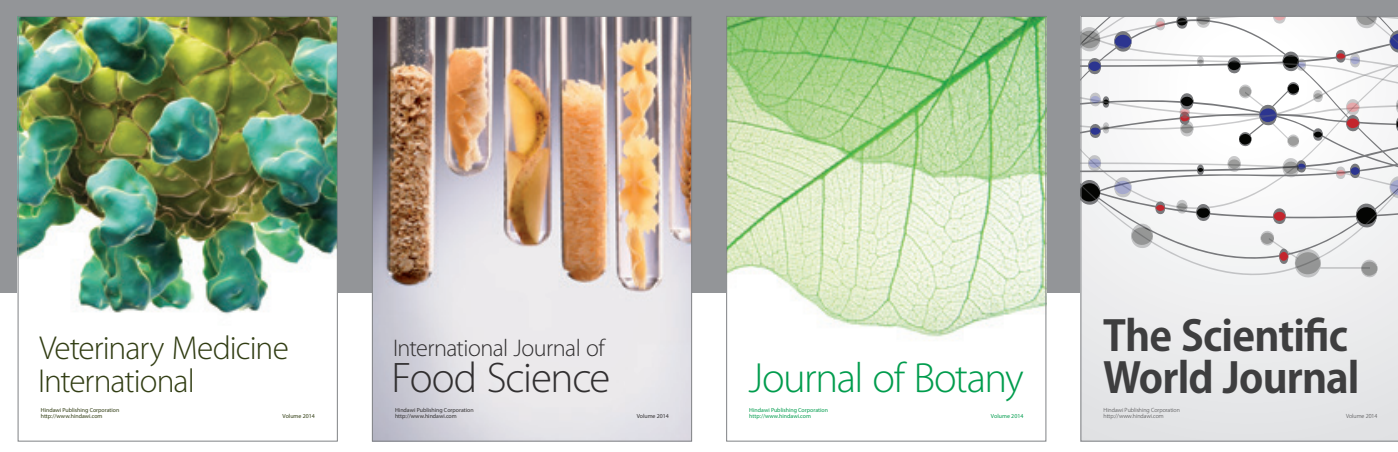

The Scientific

\section{World Journal}

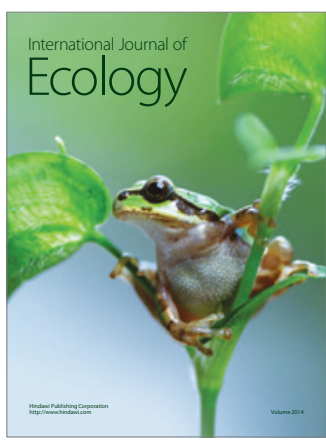

\section{Hindawi}

Submit your manuscripts at

https://www.hindawi.com
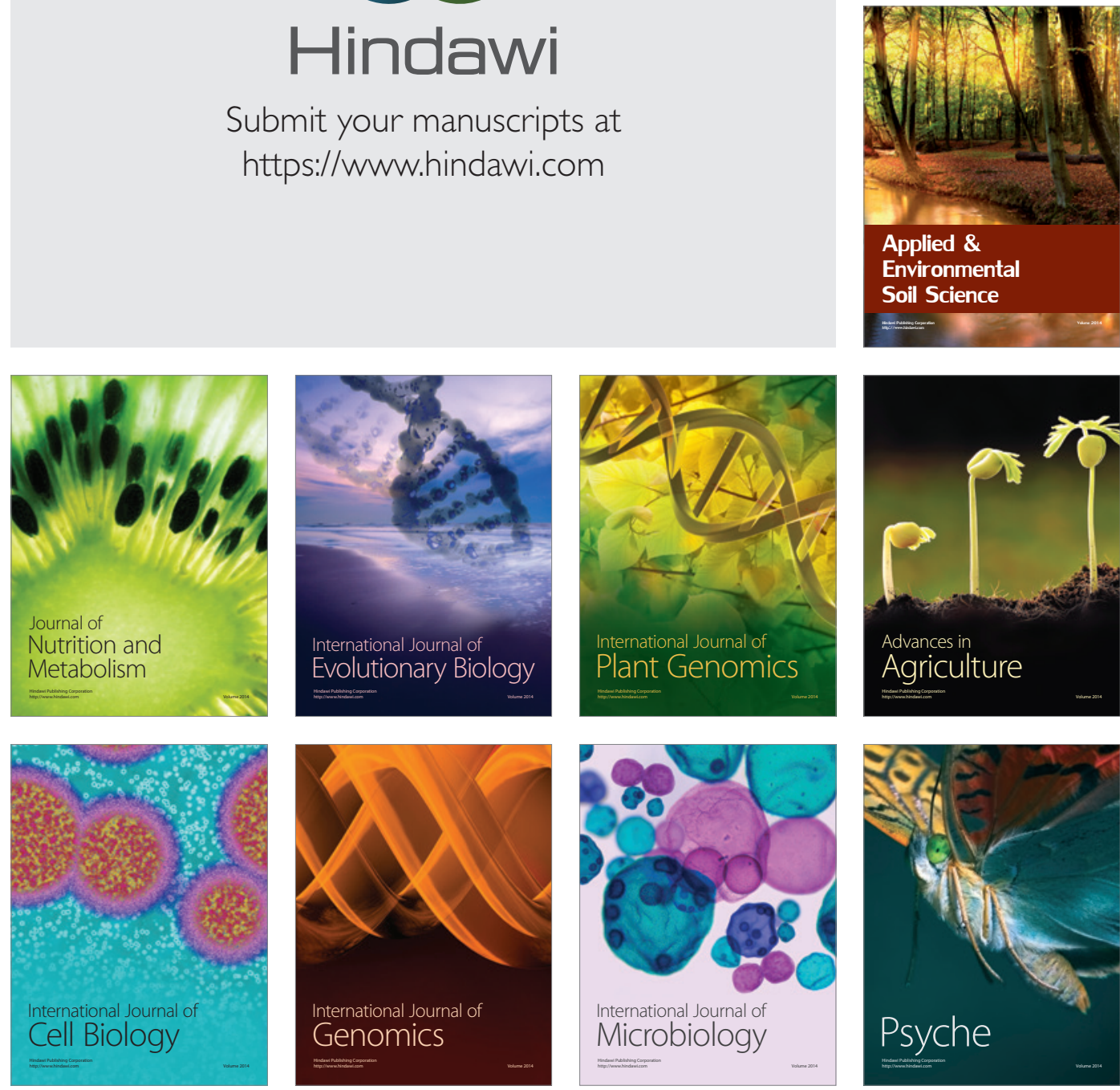
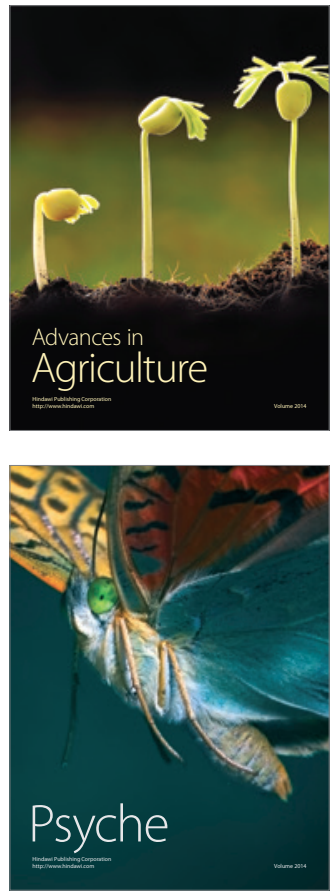